\title{
ICMI Awards Ceremony
}

\author{
Carolyn Kieran and Jeremy Kilpatrick
}

The segment of the ICME-13 Opening Ceremony that was dedicated to the ICMI Awards was presided over by Carolyn Kieran, Chair of the Felix Klein and Hans Freudenthal Awards Committee, and by Jeremy Kilpatrick, Chair of the Emma Castelnuovo Award Committee.

ICMI has awarded the Felix Klein and Hans Freudenthal medals in each of the odd-numbered years since 2003 to recognize outstanding accomplishments in mathematics education research:

- The Felix Klein Award, named after the first president of ICMI (1908-1920), for lifetime achievement in mathematics education research,

- The Hans Freudenthal Award, named after the eighth president of ICMI (19671970), for a major cumulative programme of research on mathematics education.

The Felix Klein medal acknowledges those excellent scholars who have shaped our field over their lifetimes. Past candidates have been influential and have had an impact both nationally within their own country and internationally. We have valued in the past those candidates who not only have made substantial research contributions, but also have introduced new ideas, perspectives, and critical reflections. Additional considerations have included leadership roles, mentoring, and peer recognition, as well as the actual or potential relationship between the research done and improvement of mathematics education at large, through connections between research and practice.

\author{
C. Kieran $(\square)$ \\ Université du Québec à Montréal, Montreal, QC, Canada \\ e-mail: kieran.carolyn@uqam.ca \\ J. Kilpatrick \\ University of Georgia, Athens, GA, USA \\ e-mail: jkilpat@uga.edu \\ (C) The Author(s) 2017


The Hans Freudenthal medal acknowledges the outstanding contributions of an individual's theoretically robust and highly coherent research programme. It honours a scholar who has initiated a new research programme and has brought it to maturation over the past 10 years. The criteria for this award are depth, novelty, sustainability, and impact of the research programme on our community.

In 2013 the ICMI Executive Committee decided to create a third award to recognize outstanding achievements in the practice of mathematics education, thus reflecting an aspect of the ICMI mission not previously recognized in the form of an award:

- The Emma Castelnuovo Award, named after the Italian mathematics educator born in 1913 to celebrate her 100th birthday and honour her pioneering work.

The Emma Castelnuovo medal, which is presented for the first time this year, will be awarded every four years henceforth. This medal is aimed at honouring persons, groups, projects, institutions or organizations engaged in the development and implementation of exceptionally excellent and influential work in the practice of mathematics education, such as: classroom teaching, curriculum development, instructional design (of materials or pedagogical models), teacher preparation programs and/or field projects with a demonstrated influence on schools, districts, regions or countries. The award seeks to recognize and to encourage efforts and ideas, and their successful implementation in the field.

At the 2016 Awards Ceremony, where the ICMI President, Ferdinando Arzarello, presented each awardee with a medal and certificate (see the texts of the certificates below), the following individuals were honoured:

- Felix Klein Medal for 2013: awarded to Michèle Artigue, Emeritus Professor, Université Paris Diderot—Paris 7, France.

- Hans Freudenthal Medal for 2013: awarded to Professor Frederick K. S. Leung, The University of Hong Kong, SAR China.

- Felix Klein Medal for 2015: awarded to Alan J. Bishop, Emeritus Professor of Education, Monash University, Australia.

- Hans Freudenthal Medal for 2015: awarded to Professor Jill Adler, University of the Witwatersrand, South Africa.

- Emma Castelnuovo Medal for 2016: awarded jointly to Professors Hugh Burkhardt and Malcolm Swan of the University of Nottingham, United Kingdom.

The sixth Felix Klein Medal of the International Commission on Mathematical Instruction is awarded to Professor Michèle Artigue. This distinction acknowledges her more than thirty years of sustained, consistent, and outstanding lifetime achievements in mathematics education research and development. Michèle Artigue's scholarly work in areas as diverse as advanced mathematical thinking, the role of technological tools in the teaching and learning of mathematics, institutional considerations in the professional development of teachers, and the articulation of didactical theory and methodology, is matched by a record of 
exceptional service to the international and national mathematics education communities, to graduate students and young researchers around the world, and to teacher education.

The sixth Hans Freudenthal Medal of the International Commission on Mathematical Instruction is awarded to Professor Frederick K. S. Leung. This distinction recognizes his research in comparative studies of mathematics education and the influence of culture on mathematics teaching and learning. Using the perspective of the Confucian Heritage Culture to explain the superior mathematics achievement of East Asian students in international studies and the differences in teacher knowledge between East Asian and Western countries, Frederick Leung's research has opened up a new dimension of looking at mathematics achievement and classroom practices from the perspective of culture and has had an important impact on policies and practices in mathematics education in East Asian countries and beyond.

The seventh Felix Klein Medal of the International Commission on Mathematical Instruction is awarded to Professor Alan J. Bishop. This distinction acknowledges his more than forty-five years of sustained, consistent, and outstanding lifetime achievements in mathematics education research and scholarly development. His research has been instrumental in bringing the political, social, and cultural dimensions of mathematics education to the attention of the community. Few researchers can match his impressive activity in advising prospective and practicing teachers of mathematics, encouraging them to conduct and use research in their practice. Alan Bishop has also, through his tireless and scholarly editorial work, enabled research in mathematics education to become an established field.

The seventh Hans Freudenthal Medal of the International Commission on Mathematical Instruction is awarded to Professor Jill Adler. This distinction recognizes her outstanding research dedicated to improving the teaching and learning of mathematics in South Africa, from the dilemmas of teaching mathematics in multilingual classrooms through to the problems related to mathematical knowledge for teaching and mathematics teacher professional development. Her published works have advanced the field's understanding of the relationship between language and mathematics in the classroom. Jill Adler's development of research teams and her mentoring of numerous graduate students have all added to the human research capacity she has been instrumental in creating in Southern Africa.

The first Emma Castelnuovo Medal of the International Commission on Mathematical Instruction is awarded to Professors Hugh Burkhardt and Malcolm Swan. This distinction acknowledges their more than 35 years of development and implementation of innovative, influential work in the practice of mathematics education, including the development of curriculum and assessment materials, instructional design concepts, teacher preparation programs, and educational system changes. Burkhardt and Swan have served as strategic and creative leaders of the Nottingham-based Shell Centre team of researcher-designers and their 
international collaborators. Together, Burkhardt and Swan have produced groundbreaking contributions that have had a remarkable influence on the practice of mathematics education as exemplified by Emma Castelnuovo.

Open Access Except where otherwise noted, this chapter is licensed under a Creative Commons Attribution 4.0 International License. To view a copy of this license, visit http://creativecommons. org/licenses/by/4.0/.

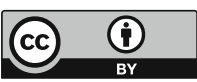

